DOI: https://doi.org/10.30749/2594-8261.v2n1p95-109

\title{
NIKLAS LUHMANN E KARL MARX: POSSÍVEL (E NECESSÁRIO) CONTRIBUTO PARA O ESTUDO DO DIREITO
}

\section{NIKLAS LUHMANN AND KARL MARX: POSSIBLE (AND NECESSARY) CONTRIBUTION TO THE STUDY OF THE LAW}

\author{
Luiz Heitor de Brito Coelho Gomes ${ }^{\mathrm{i}}$
}

Resumo: No presente estudo se vislumbra relacionar os pressupostos gerais das obras de Niklas Luhmann e Karl Marx, descrever suas lógicas de explicar a forma pela qual a ação social se ordena para, a partir disso, analisar a visão desses autores sobre o papel ocupado pelo direito na realidade social. Os pontos fundamentais das visões luhmanniana e marxiana acerca do fenômeno jurídico são analisados de modo a explicitar suas possíveis contribuições para a teoria do direito. Embora os fundamentos epistemológicos das teorias sejam diversos, tanto Luhmann como Marx apresentam visões objetivistas acerca do fenômeno jurídico, que decorrem das próprias formas de análise da organização social propostas pelos autores. Ambas as construções teóricas salientam a natureza contextual do sentido, em oposição a concepções prevalentes no âmbito da teoria do direito, que costumam atribuir um certo caráter universalista ao fenômeno jurídico.

Palavras-chave: Teoria sistêmica. Autopoiesis. Superestrutura. Equivalência das relações materiais de produção.

\begin{abstract}
In the present study, it is intended to relate the general assumptions of the works of Niklas Luhmann and Karl Marx, to describe their logic of explaining the way in which social action is ordered to analyze their view of the role of right in social reality. The fundamental points of the Luhmannian and Marxian views on the legal phenomenon are analyzed in order to make explicit their possible contributions to the theory of law. Although the epistemological foundations of the theories are diverse, both Luhmann and Marx present objectivist views about the juridical phenomenon, which derive from the many different forms of analysis of social organization proposed by the authors. Both theoretical constructions emphasize the contextual nature of meaning, as opposed to prevailing conceptions within the scope of the theory of law, which usually assign a certain universalist character to the juridical phenomenon.
\end{abstract}

Keywords: Systemic theory. Autopoiesis. Superstructure. Equivalence of material production relations.

\footnotetext{
' Mestrando em Sociologia e Direito pela Universidade Federal Fluminense, UFF.
} 


\section{INTRODUÇÃO}

Atualmente, a principal preocupação dos chamados autores de teoria do direito tem se destinado a responder de que forma discursos racionais podem proporcionar soluções práticas, que estejam em concordância com os mesmos. Parte-se de um mesmo pressuposto lógico: a sociedade se forma e reforça pela racionalização das ações dos indivíduos em sociedade, seja em seu tipo instrumental, seja em sua vertente comunicacional.

Tanto que quando se fala em teoria do direito, logo se remete a autores com esta perspectiva, como John Rawls e Jurgen Habermas, entre outros que levam tal orientação adiante, sobretudo destacando as especificidades dos mundo jurídico, às vezes de forma intelectualmente mais refinada, como o faz Robert Alexy, outras vezes desprovidos de fundamentação filosófica mais sofisticada, como é o caso de Ronald Dworkin.

Fato é que a maioria das discussões de teoria do direito tem se limitado ao debate entre essas tendências afins, abordando o direito como uma espécie de elemento de racionalização da interação social. Essa pode ser a chave para entender por que existem pensadores, cujas obras e contribuições teóricas não aparecem em destaque na teoria jurídica, ao revés, parecem receber um certo desprezo pelos juristas. Esse é o caso de Niklas Luhmann e Karl Marx, autores cujas reflexões, embora há muito sejam reconhecidas no âmbito de outras ciências sociais, sobretudo a sociologia, não costumam integrar o rol de leitura dos chamados "intelectuais do direito".

$\mathrm{Na}$ direção contrária, o presente estudo tem por objetivo analisar os pontos fundamentais das visões luhmanniana e marxiana acerca do fenômeno jurídico, de modo a explicitar as interessantes contribuições para o âmbito da teoria do direito. Embora a escrita do texto se apoie na metodologia de revisão bibliográfica, trata-se de uma proposta analítica de abordagem das inovações teóricas trazidas pelos autores ao acúmulo conceitual de possíveis interpretações sobre o direito, especialmente acerca da posição que o mesmo ocupa nas relações sociais. 
Como o conceito de sociedade é abstrato, a compreensão do direito inserido na estrutura social só pode ocorrer a partir do entendimento de modelos teóricos mais amplos, o que exige acompanhamento das lógicas de raciocínio arquitetadas para sua formulação. Dessa forma, o que se vislumbra aqui é relacionar os pressupostos gerais das obras de Luhmann e Marx, descrever suas lógicas de explicar a forma pela a ação social se ordena e, a partir disso, explicitar a visão desses autores sobre o papel ocupado pelo direito na realidade social.

\section{A TEORIA SISTÊMICA DO DIREITO DE NIKLAS LUHMANN}

A sociologia luhmanniana do direito se difere da que pode ser chamada de teoria sistêmica do direito, pela razão de que esta última pode ser tomada como derivação daquela. Para Luhmann, a complexidade do mundo humano decorre do fato de os comportamentos serem necessariamente mediados pela comunicação, ou seja, pelo fato de eles serem importantes por terem um sentido, por constituírem mensagens (MELLO, 2006).

A concepção luhmanniana parte da ideia de que os comportamentos humanos seguem uma determinada lógica, estando o autor preocupado em perquirir os fundamentos da ordem social. Nesse sentido, o grande problema de sua sociologia é estudar a natureza da organização social, buscar alguma previsibilidade em meio à contingência, partindo da ideia de que a interação precisa de elementos sociais previamente constituídos.

Tal estabilização, na concepção de Luhmann, depende de sistemas comunicativos que sejam capazes de dar às ações um sentido compartilhado pelos seus interlocutores, numa clara negação da existência de sentidos universais para os atos humanos. A redução da complexidade da vida social passa, então, por uma redução da ambiguidade dos atos humanos, na tentativa de fixar sentidos esperados, estáveis (HESPANHA, 2009).

É por isso que a sociologia do direito de Max Weber, caracterizada pelo subjetivismo do sentido, é duramente criticada por Luhmann, pois segundo ele é incapaz de explicar de modo satisfatório a necessidade de diminuição da 
contingência e passagem para uma maior previsibilidade. Na visão luhmanniana, embora rica em material concreto, a sociologia Weberiana possui uma acentuação unilateral, correspondente ao interesse que a orienta - indagação quanto à racionalização como traço fundamental do desenvolvimento da sociedade europeia, principalmente nos tempos modernos - e, além disso, seu fundamento teórico é insuficientemente desenvolvido, faltando-lhe uma concepção de racionalidade social destacável da ação individual (LUHMANN, 1983).

A teoria sistêmica luhmanniana representa, assim, uma ruptura com o paradigma subjetivista, pois desloca o foco das questões relativas às interpretações e aos acordos cognitivos entre os indivíduos para a análise dos sistemas sociais, que apresenta seus códigos próprios (MELLO, 2006). A explicação de Luhmann sobre como as ações sociais ganham um caráter ordenado vem através da ideia de sistemas sociais e, assim, o direito assume grande relevância na sua teoria sociológica, pois aparece como um sistema estruturado que, ao operar a redução das complexidades, acaba incrementando na sociedade elementos de natureza previsível.

A abordagem do ordenamento jurídico como uma construção de alta complexidade estruturada enfatiza que o direito exerce uma função essencial, se não decisiva, no alcance de uma complexidade mais alta e estruturada em sistemas sociais. Nesse sentido, o autor destaca a necessidade de compreender o direito como estrutura e a sociedade como sistema em uma relação de interdependência recíproca (LUHMANN, 1983).

A teoria sistêmica do direito reconhece a contingência como presente em toda interação humana, porque as formas de agir não se baseiam apenas na expectativa que o indivíduo tem, mas também nos anseios que o outro possui:

Reconhecer e absorver as expectativas de um outro como minhas próprias só é possível se reconheço o outro como um outro eu. Essa é a garantia da propriedade da nossa experiência. Com isso, porém, tenho que conceder que o outro possui igualmente a liberdade de variar seu comportamento, da mesma forma que eu. Também para ele o mundo é complexo e contingente. Ele pode errar, enganar-se, enganar-me. Sua intenção pode provocar minha decepção. O preço da absorção de perspectivas estranhas é, formulado, em termos extremos, sua confiabilidade (LUHMANN, 1983, p.47). 
Contudo, ele destaca a possibilidade de reduzir o desapontamento, pois frente à contingencia aparecem estruturas estabilizadas de expectativas, mais ou menos imunes a desapontamentos - colocando as perspectivas de que à noite segue o dia, de que amanhã a casa ainda estará de pé, que a colheita está garantida, que as crianças crescerão... (LUHMANN, 1983, p.46). Nesse quadro, é que na sociologia jurídica luhmanniana o campo normativo aparece como importante fator redutor de complexidade, havendo pouco espaço para transações:

O direito, na verdade permite essa generalização, garantia e consequente estabilização das expectativas porque formula modelos de comunicação, ao criar um conhecimento prático e difuso das estatuições das normas jurídicas, depois ainda reforçado por um conhecimento especializado (dogmática jurídica) para o qual se reclama uma inevitabilidade que se pretende próxima da das ciências ("ciência" jurídica...). Garante/solidifica as expectativas, (i) ao impor normas desincentivadoras (punitivas) dos factos que frustrem expectativas, (ii) ao promover por meio de vantagens os comportamentos correspondentes ao esperado e (iii) ao difundir a convicção de que isto resulta ou da natureza ou de valores obrigatórios à luz da razão ou da prudência (HESPANHA, 2009, p.215).

As estruturas sistêmicas, ao delimitarem o campo da contingência, provocam um certo efeito aliviante, pois a redução das expectativas torna possível estabelecimento de referências. Isso permite, em um mundo extremamente complexo, a realização de reduções que possibilitem expectativas comportamentais recíprocas, orientadas a partir das expectativas sobre tais expectativas.

Nesse sentido, há uma diferenciação de expectativas, pois as de natureza cognitiva abrem mais chance para o desapontamento, ao passo que as de natureza normativa são expectativas de comportamentos contra fáticos, pois o sistema independe dos elementos contingentes que possam aparecer (LUHMANN, 1983).

Dessa forma, no campo normativo as expectativas são mais fechadas, óbvias, de modo que a transgressão não é, sequer, levada a sério, sendo o comportamento divergente, considerado anormal que, por agir tão fora da expectativa normativa, é considerado caso isolado, não sendo considerado ameaça, 
pois as estruturas sistêmicas não são ameaçadas, eximindo-se de qualquer problematização (LUHMANN, 1983).

O direito possui, então, a função de generalização congruente das expectativas normativas, garantindo uma maior previsibilidade e menor contingência das possibilidades comportamentais:

O direito é imprescindível enquanto estrutura, porque sem a generalização congruente de expectativas comportamentais os Homens não podem orientar-se entre si, não podem esperar suas expectativas. E essa estrutura tem que ser institucionalizada ao nível da própria sociedade, pois só aqui podem ser criadas aquelas instâncias que domesticam o ambiente para outros sistemas sociais. Ele modifica, portanto, com a evolução da complexidade social (LUHMANN, 1983, p.170).

Desse modo, na ótica Luhmanniana a sociedade aparece como um sistema de sistemas, sendo o direito a própria estrutura desses sistemas sociais, o que lhe confere especial importância, pois o direito é a própria ordem. Isso confere ao direito, nos termos do autor, um caráter estruturante, na medida em que é um sistema que penetra em todos os sistemas, regulando-os e permitindo a discussão quanto a elementos que nem se sabe quais serão (LUHMANN, 1983).

Outro conceito importante para a compreensão de sua teoria é a ideia de autopoiesis ou capacidade de autocriação do sistema, de modo que se fecha ao ambiente, não se deixando influenciar por regras que lhe sejam estranhas. No entanto, é preciso cuidado na análise:

Tal como os sistemas biológicos - os seres vivos -, por exemplo, constituem um sistema autopoiético, mas recebem energia (alimentos, calor etc.) do ambiente assim como são irritados por ele e reagem por auto adaptações, a essas irritações, também o direito mantém uma relação semelhante de fechamento/abertura com o seu ambiente (o sistema político, a economia, o senso comum etc. Assim, a sua energia (força coercitiva de suas normas) advém-lhe do sistema político, da garantia do Estado, ou do senso comum, da disponibilidade das pessoas para aceitarem o direito. Ao mesmo tempo, o que passa no ambiente do sistema irrita o sistema obrigando-o a reajustar-se internamente, em ordem a produzir resultados que the causem menos irritação (HESPANHA, 2009, p.220). 
Nesse sentido, embora na visão luhmanniana os sistemas sejam autopoiéticos e autorreferentes, tal fato não impede que sejam cognitivamente abertos: a clausura dos sistemas consiste justamente em sua condição de abertura sendo que apesar de aparentemente paradoxal, os sistemas são fechados, porque são abertos: e são abertos, porque são fechados (MELLO, 2006).

Luhmann (1983) chama de dupla contingência dos sistemas o fato de eles operarem de maneira normativamente fechada e, ao mesmo tempo, cognitivamente aberta, na qual a assimetria entre o sistema e seu ambiente os força a uma recíproca adaptação e mudança, o que requer relações simétricas entre seus componentes, na medida em que um elemento dá sustentação ao outro e viceversa.

Assim, Luhmann mostra que, conforme as sociedades vão se complexificando, mais o direito vai ganhando caráter integrador na medida em que se destacam algumas características do seu caráter estruturante. $E$ isso, porque ele é modificável, podendo acompanhar as mudanças de caráter estrutural, pois é estimulado por informações do ambiente (cognitivamente aberto). Contudo, a norma só pode ser alterada por outra norma, pois, embora possa haver influência política, somente a lei pode modificar a lei (normativamente fechado) (LUHMANN, 1983).

Nesse sentido, a mirada lumanniana do fenômeno jurídico revela que não é apenas a realidade da interação entre os atores sociais que cria o direito, pois ele também possui função criadora da realidade social, haja vista que seu código próprio de licitude-ilicitude faz com que as ações se reordenem conforme a lógica jurídica que as permeia.

\section{O DIREITO EM KARL MARX: DA SUPERESTRUTURA À EQUIVALÊNCIA DAS RELAÇÕES MATERIAIS DE PRODUÇÃO}

De antemão, é preciso dizer que embora seja possível encontrar uma teoria do direito em Marx, ela não aparece "pronta". À primeira vista, parece natural a tentativa de compreender a natureza do direito em Marx, a partir das obras em que a temática jurídica aparece de forma clara, como no caso das chamadas obras de 
juventude do autor, dentre as quais se destacam sua "Crítica da filosofia do direito de Hegel" e "A ideologia Alemã".

Sem dúvida, tais trabalhos constituem uma ruptura fundamental na trajetória intelectual de Marx, conferindo as bases sobre as quais se assentaria o materialismo histórico. Contudo, em "O capital" o autor também nos oferece base teórica indispensável à compreensão de sua ótica sobre o fenômeno jurídico.

Como dito, a abordagem marxiana do estudo das sociedades se dá através de um método de análise o qual se convencionou chamar de materialismo histórico, pelo qual o autor procura as razões para as continuidades e mudanças nas relações sociais, examinando as formas pelas quais os homens produzem sua vida material, seus meios de existência (MARX; ENGELS, 1999).

Em suma, a organização da sociedade é produto da relação dos indivíduos com o espaço físico no qual estão inseridos - condições materiais de produção -, que são fundamentais para o desenrolar do desenvolvimento histórico. O que revela os modos diferenciados de organização das sociedades é, precipuamente, a forma pela qual os homens se relacionam entre si para fins de apropriação e transformação da natureza, de modo a satisfazer suas necessidades.

Tal afirmativa se confirma quando Marx e Engels (1999) apresentam uma distinção entre as diferentes sociedades (tribais, comunitária estatal, a propriedade feudal ou por ordens, propriedade corporativa tribos indígenas e sociedade inglesa) a partir do estágio de desenvolvimento da divisão do trabalho, que segundo ele determina não só as relações entre os indivíduos no que toca aos instrumentos e produtos do trabalho, como também às diferentes formas de propriedade nelas presentes.

Dessa forma, podemos dizer que no período que remete às chamadas obras de juventude, especialmente a crítica da filosofia do direito de Hegel e A ideologia alemã, temos uma concepção marxiana fundada em uma verdadeira teoria da história, na qual o primeiro ato é a produção de meios que satisfaçam às necessidades humanas:

Relativamente aos alemães, que se julgam desprovidos de qualquer pressuposto, devemos lembrar a existência humana e, portanto, de 
toda a história, a saber, que os homens devem estar em condições de poder viver a fim de "fazer história". Mas, para viver, é necessário, antes de mais beber, comer, ter um teto onde se abrigar, vestir-se etc. O primeiro fato histórico é, pois, a produção dos meios que permitem satisfazer as necessidades, a produção da própria vida material; trata-se de um fato histórico, de uma condição fundamental de toda a história, que é necessário, tanto hoje quanto a milhares de anos, executar dia a dia, hora a hora, a fim de manter os homens vivos (MARX, 1999, p. 30)

Essa fase da obra de Marx é marcada pelo desbaratamento das concepções ideológicas e abstratas da história, sendo apenas a partir da observação do mundo real que se pode compreender as formas ordenação social. Interessante notar que aqui Marx está constituindo um sistema de pensamento próprio, rompendo o referencial teórico anterior, o qual denomina de idealismo alemão, cuja maior expressão se encontra em Hegel:

(...) Por isso, a tarefa da história, depois que o além da verdade se desvaneceu, é estabelecer a verdade do aquém. A imediata tarefa da filosofia, que está ao serviço da história, é desmascarar a auto alienação humana nas suas formas não sagradas, agora que ela foi desmascarada na sua forma sagrada. A crítica do céu transforma-se deste modo em crítica da terra, a crítica da religião em crítica do direito, a crítica da teologia em crítica da política. (...) A crítica da filosofia alemã do direito e do Estado, que teve a mais lógica, profunda e completa expressão em Hegel, surge ao mesmo tempo como a análise crítica do Estado moderno e da realidade a ele associada e como a negação definitiva de todas as anteriores formas de consciência na jurisprudência e na política alemã, cuja expressão mais distinta e mais geral, elevada a ciência, é precisamente a filosofia especulativa do direito (MARX, 2008, p. 06 e 13).

Contudo, não se pode cair no equívoco de imaginar que em Marx seja possível uma compreensão histórica a partir apenas dos elementos concretos da vida social. Tanto é assim, que em a ideologia alemã o autor critica os materialistas, chamados por ele de jovens hegelianos, exatamente porque, ao desconsiderarem a filosofia como elemento fundamental, parte integrante da realidade concreta alemã, acabam se igualando ao idealismo hegeliano: 
(...) É com razão, pois, que o partido político prático na Alemanha exige a negação da filosofia. O seu erro não consiste em formular tal exigência, mas em limitar-se a uma exigência que ele não leva, nem pode levar a cabo. Crê que é capaz de realizar esta negação voltando as costas à filosofia, de cabeça virada par outro lado murmurando umas quantas frases triviais e mal-humoradas. Devido à sua tacanha maneira de ver, não considera a filosofia como parte da realidade alemã e considera até a filosofia como abaixo do nível da vida prática alemã e das teorias que a servem. Como ponto de partida exige-se o real germe de vida, mas esquece-se de que o real germe de vida do povo alemão só nasceu, até agora, no seu crânio. Em suma, é impossível abolir a filosofia sem a realizar (...) (MARX, 2008, p.12).

Tal ressalva de modo algum infirma a premissa da concepção materialista marxiana, no sentido de que as ideias se explicam a partir da realidade, não o contrário. Ora, se na base do materialismo histórico as formas de pensamento estão sempre ligadas às condições materiais da sociedade em que estão sendo elaboradas, as ideias só podem ser compreendidas mediante as relações sociais de produção na qual estão sendo construídas:

(...) O mesmo erro foi cometido, mas em sentido oposto, pela facção teórica que se originou na filosofia. Na presente luta, esta facção viu apenas o combate crítico da filosofia contra o mundo alemão; não considerou que também a anterior filosofia pertence a este mundo e constitui o seu complemento, embora seja apenas um complemento ideal. Crítica no que respeita à sua contraparte, é acrítica em relação a si própria. Tomou como ponto de partida os pressupostos da filosofia; e ou aceitou as conclusões a que a filosofia chegara, ou apresentou como exigências e conclusões filosóficas imediatas exigências e conclusões que derivou de qualquer outro campo. Mas estas - supondo que são legítimas - só podem obter-se mediante a negação da filosofia anterior, isto é, da filosofa enquanto filosofia. Fornecemos, à frente, uma descrição mais pormenorizada desta facção. O seu principal defeito pode resumir-se assim: pensou que poderia realizar a filosofia, sem a abolir (...) (MARX, 2008, p.13).

No mesmo sentido, em sua crítica da filosofia de Hegel, Marx constrói linha de raciocínio contrária à concepção idealista hegeliana, sobretudo a que se destina a explicar as questões do Estado e do seu direito público interno. Naquela obra, em síntese, o autor associa a compreensão das relações jurídicas na sociedade com as 
relações materiais, desenvolvendo sua atitude crítica em relação ao Estado como negação do indivíduo e não a realização de sua essência, como pressupõe Hegel.

O direito surge, então, das relações econômicas, legitimando a ascensão da burguesia como classe social dominante e refletindo as formas materiais de dominação classistas. Vale ressaltar que em Marx os interesses egoísticos particulares fazem parte da estrutura do Estado, que é a essência alienada da sociedade civil, espaço de conflitos, não de conciliação.

Nesse sentido, novamente, ele se opõe à concepção hegeliana, que coloca o direito como uma espécie de justificativa filosófica da existência Estado. Ora, se pra Marx o direito é reflexo da vida material, quando situado no campo das ideias não seria diferente, pois o pensamento dominante expressa exatamente as formas reais de dominação:

Os pensamentos da classe dominante são também, em todas as épocas, os pensamentos dominantes, ou seja, a classe que detém o poder material dominante numa dada sociedade é também a potência dominante espiritual. A classe que dispõe dos meios de produção material dispõe igualmente dos meios de produção intelectual, de tal modo que o pensamento daqueles a quem são recusados os meios de produção intelectual está submetido igualmente à classe dominante. Os pensamentos dominantes são apenas a expressão ideal das relações materiais dominantes concebidas sob a forma de ideias e, portanto, a expressão das relações que fazem de uma classe a classe dominante (MARX; ENGELS, 1999, p. 62).

Desse modo, já na formulação teórica do jovem Marx as concepções idealistas e imaginárias do direito são retiradas de cena, só podendo o fenômeno jurídico ser encontrado nas condições reais de vida dos homens, quer dizer, nas condições de produção e nas forças produtivas. Assim, a teoria marxiana das obras de juventude estabelece uma determinação entre as condições materiais econômicas e as formas ideológicas, políticas e jurídicas, compreendendo o direito é como um instrumento da classe dominante, expressão imediata dos seus interesses (NAVES, 2014, p. 32).

Em outros termos, a estrutura material que determina o modo de produção da vida social na sociedade é sua infraestrutura econômica, que acaba 
determinando a superestrutura jurídica, sendo que esta reflete as relações materiais de produção (MARX; ENGELS, 1999). Nesse sentido, o fenômeno jurídico aparece na sociedade capitalista como um fenômeno superestrutural, cuja razão de existir consiste na garantia de estabilidade oferecida pelo Estado, no sentido de que os interesses da classe dominante estarão assegurados.

No entanto, já é um entendimento relativamente generalizado entre os estudiosos de Marx que sua leitura do direito não se resume a reconhece-lo apenas como elemento superestrutural, que se encaixa na estrutura produtiva/econômica da sociedade. Como antecipado, é na obra "O capital" que o autor fornece os elementos conceituais para a compreensão de que em sua ótica o fenômeno jurídico não é uma esfera que apenas reflete as relações de produção, mas sobretudo que a reprodução do capital também depende, em essência, da existência do direito.

Naves (2014), com propriedade, defende que a concepção marxiana do direito depende da explicação da própria existência do direito, enquanto um tipo específico da sociedade capitalista. Em outras palavras, aquilo que se entende como direito antes da sociedade capitalista, a rigor, não é direito, pois sua compreensão não permite distinguir a forma jurídica de outras formas de organização social, como a religião, o misticismo ou a política.

Assim, para a definição do conteúdo do direito é importante apreender aquilo que o distingue das outras formas de organização social, o que só é possível, de fato, na sociedade capitalista. Isso porque a natureza do direito reside especificamente na subordinação do trabalho ao capital, acompanhada da relação de equivalência na qual os homens estão reduzidos a uma unidade comum de medida, oriunda daquela subsunção (PACHUKANIS, 2017).

Essa leitura marxiana permite dizer que onde essa equivalência não existe, pode haver relação de poder, mas não relação jurídica em sua forma específica. Em outros termos, se excluirmos o critério de equivalência, não seria possível distinguir uma norma política de uma norma jurídica (NAVES, 2014, p. 86). Desse modo, a compreensão marxiana do fenômeno jurídico, tomando como referência sua obra de maturidade revela que a forma abstrata de um sujeito provido de capacidade jurídica é a correspondência equivalente do modo de produção específico da sociedade capitalista. 
Nesse raciocínio, a noção de sujeito de direito e a ideologia jurídica constituem a base na qual se assentam as relações mercantis, sendo necessário que os indivíduos sejam reconhecidos juridicamente como iguais em direitos e livres para celebrar negócios e contratos de modo a regular as trocas econômicas:

\begin{abstract}
A troca de mercadorias, por si só, não implica quaisquer outras relações de dependência além daquelas que resultam de sua própria natureza. Sob esse pressuposto, a força de trabalho só pode aparecer como mercadoria no mercado na medida em que é colocada à venda ou é vendida pelo seu próprio possuidor, pela pessoa da qual ela é a força de trabalho. Para vende-la como mercadoria, seu possuidor tem de poder dispor dela, portanto ser livre proprietário de sua capacidade de trabalho. Ele e o possuidor de dinheiro se encontram no mercado e estabelecem uma relação mútua como iguais possuidores de mercadorias, com uma única diferença de que um é comprador e o outro vendedor, sendo ambos, portanto, pessoas juridicamente iguais (MARX, 2013, p. 242).
\end{abstract}

Desse modo, a análise da concepção marxiana do direito possibilita perceber como o fenômeno jurídico intimamente ligado às relações de produção e trocas mercantis na sociedade capitalista, ao mesmo tempo em que está longe de se limitar a refleti-las. Como no capitalismo a base do modo de produção é a submissão do trabalho ao capital, sendo o jurídico a equivalência necessária que permite essa subordinação, o direito constitui a própria essência do sistema, possibilitando a continuidade do processo de produção/reprodução do sistema capitalista.

\title{
4 CONSIDERAÇÕES FINAIS
}

Como procuramos demonstrar, embora os fundamentos epistemológicos das teorias luhmanniana e marxiana sejam diversos, a teoria sistêmica e o conceito de direito em Marx possuem traços comuns que as singulariza diante de outras concepções teóricas sobre o fenômeno jurídico.

Tanto Luhmann como Marx apresentam visões objetivistas acerca do fenômeno jurídico, que decorrem da própria visão de sociedade dos autores. $\mathrm{Na}$ 
mesma esteira, ambas as construções teóricas salientam a natureza contextual do sentido, em oposição a concepções universalistas acerca do direito.

Como visto, o instrumental teórico luhmanniano busca explicar o sistema jurídico a partir da função precípua de redução de complexidade apresentada pelos sistemas sociais, por via do que chama de generalização de expectativas normativas. Em outros termos, na formulação de Luhmann o direito é um sistema autopoietico, cuja função essencial é estabilizar expectativas comportamentais, disponibilizando caminhos congruentes para as mesmas. Contudo, embora o direito reproduza os elementos em seu interior, sua abertura cognitiva faz com que captem informações do ambiente numa relação recíproca.

Observamos, por sua vez, que a leitura marxiana mais atenta organiza os conceitos desenvolvidos pelos autor, demonstrando que nas relações sociais há sempre um jogo de ações e reações entre os fatores jurídico, político, filosófico e econômico. Dessa forma, além de possuir apenas uma relação causal reflexiva em relação à economia, o direito tem papel constitutivo da vida social, também determinando as formas comportamentais de expressão.

Desse modo, vimos que tanto em Marx como em Luhmann o fenômeno jurídico possui características próprias, não podendo ser considerado mero reflexo das relações sociais, mas também formador da ordem social concreta, o que lhes confere importância singular no estudo da teoria do direito.

Após percorrer alguns conceitos fundamentais dos universos teóricos luhmanniano e marxiano, é possível retomar a hipótese aventada na introdução, para reafirmar a importância de tais análises para o direito. Em outras palavras, partindo do pressuposto de que o fenômeno jurídico só pode ser compreendido no contexto da ordem social complexa, o estudo de teoria do direito jamais poderá se desinteressar por esses autores.

\section{REFERÊNCIAS}

HESPANHA, Antônio Manuel. O caleidoscópio do Direito: o direito e a justiça nos dias e no mundo de hoje. $2^{\mathrm{a}}$ ed. Coimbra: Almedina, 2009. 
LUHMANN, Niklas. Sociologia do direito. Rio de Janeiro: Tempo Brasileiro, 1983. Volume I.

MARX, Karl. Para a Crítica da Filosofia de Hegel: Introdução. Covilhã: Lusosofia press, 2008.

. O Capital: crítica da economia política: livro I: O processo de produção do capital. São Paulo: Editora Boitempo, 2013.

MARX, Karl; ENGELS, Friedrich. A Ideologia Alemã: primeiro capítulo. [s.I.]: Ridendo Castigat Mores, 1999. Disponível em:

<http://www.ebooksbrasil.org/adobeebook/ideologiaalema.pdf>. Acesso em: 4 abr. 2018.

MELLO, Marcelo Pereira de. A perspectiva sistêmica na sociologia do Direito: Luhmann e Teubner. Tempo Social: revista de Sociologia da USP, São Paulo, v. 18, n. 1, p. 351-373, 2006. Disponível em:

<http://www.scielo.br/pdf/ts/v18n1/30021.pdf>. Acesso: 4 abr. 2018.

NAVES, Márcio Bilharinho. A questão do Direito em Marx. São Paulo: Outras Expressões; Dobra Universitário, 2014.

PACHUKANIS, Evguiéni B. Teoria geral do direito e marxismo. São Paulo: Boitempo, 2017.

SECRETARIA NACIONAL DE FORMAÇÃO POLÍTICA DO PARTIDO COMUNISTA BRASILEIRO. Modos de Produção. Disponível em:

<http://www.pcb.org.br/portal/docs/modosdeproducao.pdf>. Acesso em: 21 nov. 2016. 